\title{
A experiência corporal de um adolescente com transtorno alimentar*
}

Thais Fonseca de Andrade

Manoel Antonio dos Santos

Apesar do aumento de casos de jovens com anorexia nervosa, essa temática ainda constitui um tabu no universo masculino. O objetivo deste estudo é investigar o modo como um adolescente com anorexia nervosa atípica experiencia seu corpo e imagem corporal. Utilizou-se de entrevista individual semiestruturada, audiogravada e transcrita literalmente, com o paciente, sua mãe e nutricionista, além de consulta ao prontuário médico. Conclui-se que o jovem apresenta conflitos relacionados ao seu corpo e imagem corporal.

Palavras-chave: Anorexia nervosa, sexo masculino, corpo, imagem corporal

* Este trabalho foi baseado na dissertação de mestrado intitulada $O$ imaginário da perfeição: A corporeidade em homens com transtornos alimentares, apresentada à Faculdade de Filosofia, Ciências e Letras de Ribeirão Preto, Universidade de São Paulo (Ribeirão Preto, SP, Brasil), em 2008. Os autores manifestam seus agradecimentos ao GRATA - Grupo de Assistência em Transtornos Alimentares, vinculado ao Ambulatório de Nutrologia do Hospital das Clínicas da Faculdade de Medicina de Ribeirão Preto, Universidade de São Paulo (Ribeirão Preto, SP, Brasil). 


\section{Introdução}

A literatura aponta que os transtornos alimentares em homens têm uma menor prevalência do que em mulheres. Estudos apontam que a proporção homem/mulher é de 1:10, podendo variar, de acordo com os critérios utilizados, entre 1:6 e 1:20 (Andersen, 1992, 1999; Andersen; Cohn; Holbrook, 2000; Copperman, 2000).

O que se observa a partir da literatura examinada é que, até os anos 1980, questões relacionadas à imagem corporal eram vistas como uma preocupação exclusivamente feminina, porém estudos recentes demonstram que os homens também estão sofrendo com preocupações relativas à imagem corporal e isso se reflete no comportamento alimentar, na prática de exercícios físicos e na adesão às dietas (Facchini, 2006). A obsessão pela magreza e o culto ao corpo esbelto, que marcam a contemporaneidade, parecem estar afetando também jovens do sexo masculino. Dependendo de como esse imperativo sociocultural é subjetivado pelos jovens, contribui para aumentar sua vulnerabilidade e predispô-los ao desenvolvimento de transtornos alimentares.

Compreender o modo peculiar como o adolescente com transtorno alimentar vivencia seu corpo e estrutura sua imagem corporal é uma condição preliminar à organização do tratamento. Essa problemática constitui um desafio ao tratamento e à pesquisa (Andersen; Holman, 1997). O planejamento do pro- 
jeto terapêutico deve levar em conta a relação que cada paciente estabelece com seu corpo, que é mediada fortemente pela imagem inconsciente, que se estrutura e reestrutura continuamente ao longo do ciclo vital. A adolescência é um período crítico do desenvolvimento no qual a imagem corporal passa por intensa remodelagem, acompanhando as drásticas transformações corporais.

A literatura mostra que os transtornos alimentares estão intimamente vinculados ao modo como o indivíduo vivencia seu corpo e (re)organiza sua imagem corporal na travessia da adolescência. Todavia, em relação aos jovens do sexo masculino que desenvolvem transtorno alimentar, há pouco conhecimento sistematizado acerca de como essas mudanças são vivenciadas ou percebidas e como as experiências corporais afetam a imagem que eles constroem acerca de sua corporeidade. Nesse sentido, o presente estudo tem por objetivo investigar a forma como um adolescente do sexo masculino diagnosticado com anorexia nervosa atípica vivencia seu corpo e imagem corporal. Para alcançar esse objetivo relataremos o caso de um paciente do sexo masculino, com diagnóstico de anorexia nervosa atípica, acompanhado por obsessão pela prática de atividades físicas.

\section{Método}

Trata-se de um estudo do tipo exploratório descritivo, desenvolvido segundo um enfoque de pesquisa qualitativa, adotando como estratégia metodológica o estudo de caso.

De acordo com Gil (1996), a pesquisa exploratória visa a uma maior aproximação com o problema para torná-lo mais claro e explícito, ou desenvolver hipóteses. Visa, principalmente, aperfeiçoar ideias ou descobrir intuições. O estudo descritivo, segundo o mesmo autor, tem por finalidade descrever as características de determinada população ou fenômenos ou estabelecer relações entre variáveis.

Segundo Peres e Santos (2005), o estudo de caso propõe uma análise em profundidade do objeto de investigação e se preocupa com o aspecto unitário e integrado, que é resultado da combinação de diversas variáveis, sejam elas sociais, biológicas, psicológicas e culturais. Essa estratégia metodológica é adequada ao nosso objeto de estudo, uma vez que estamos interessados em compreender a fundo a totalidade desse objeto em particular, em vez de descobrir leis universais para um determinado fenômeno. 


\section{Participantes}

Participaram do estudo um adolescente, a quem chamaremos de Fernando, 18 anos, e sua mãe, aqui designada como Cássia, 53 anos, branca, casada, do lar. Filho e mãe eram oriundos de um município da região, próximo à cidade onde se desenvolveu o estudo. Além da díade mãe-filho, participou também do estudo a nutricionista responsável pelo atendimento do paciente no serviço especializado.

Em relação ao diagnóstico, a categoria anorexia nervosa atípica é aplicada a pessoas para as quais um ou mais aspectos-chave da anorexia nervosa estão ausentes, mas que, ainda assim, apresentam um quadro clínico razoavelmente típico, de acordo com a Classificação de Transtornos Mentais e de Comportamento da CID-10 (OMS, 1993).

\section{Local e cuidados éticos}

Este estudo foi realizado no GRATA, um serviço vinculado ao Ambulatório de Nutrologia do Hospital das Clínicas da Faculdade de Medicina de Ribeirão Preto - FMRP-USP (Ribeirão Preto, São Paulo, Brasil), criado em 1982. O GRATA oferece assistência a pacientes com anorexia e bulimia nervosas, bem como a seus familiares, com um enfoque multidisciplinar.

O projeto de pesquisa foi aprovado pelo Comitê de Ética em Pesquisa do Hospital das Clínicas da Faculdade de Medicina de Ribeirão Preto - HC-FMRP-USP, instituição na qual foi realizado o estudo (processo n. 8342/2006). Contou com a anuência do chefe de Departamento de Clínica Médica e do médico responsável pelo Ambulatório de Nutrologia do HC-FMRP-USP. A participação na pesquisa do paciente, de seu familiar e da nutricionista foi voluntária e formalizada por assinatura do Termo de Consentimento Livre e Esclarecido.

\section{Procedimento}

A coleta de dados foi realizada de acordo com a disponibilidade e conveniência dos participantes.

Seguindo-se os preceitos teóricos que guiam o estudo de caso, os dados foram coletados por meio de diferentes fontes e informantes: 1) entrevista semiestruturada individual realizada com o paciente, sua mãe e a nutricionista, que permitiu a produção de uma fala espontânea dos entrevistados sobre o problema

Rev. Latinoam. Psicopat. Fund., São Paulo, v. 12, n. 3, p. 454-468, setembro 2009 
alimentar, o tratamento e as relações familiares; 2) consulta ao prontuário médico do paciente para coleta de dados sociodemográficos, categoria diagnóstica, evolução clínica, estado nutricional e condição de saúde.

Segundo Yin (2005), as entrevistas são uma das mais importantes fontes de informações para um estudo de caso. Em seguida, as entrevistas foram transcritas na íntegra e literalmente. Não nos preocupamos com a correção dos aspectos gramaticais, procurando, assim, manter a linguagem dos entrevistados, numa tentativa de evitar ao máximo a distorção do sentido de suas palavras.

\section{Resultados e discussão}

\section{Identificação pessoal}

Fernando (nome fictício), 18 anos, solteiro, branco, evangélico, único filho do sexo masculino de uma prole de quatro irmãs mais velhas, na época estava cursando o segundo colegial em um curso supletivo. No período em que foi realizada a coleta de dados, encontrava-se em seguimento junto ao GRATA havia nove meses.

\section{Histórico familiar}

Fernando morava com a mãe, o pai e uma das irmãs, que é solteira. A família residia em imóvel próprio, em um conjunto residencial da $\mathrm{COHAB}$, adquirido mediante financiamento. Segundo informação colhida no prontuário médico, os pais e as irmãs eram magros; as irmãs gozavam de boa saúde, a mãe era hipertensa e o pai tinha diabetes mellitus. O paciente relatou que seu relacionamento com os familiares era muito bom.

\section{História pregressa: os percalços do percurso após a puberdade}

Fernando foi internado no Hospital das Clínicas de Ribeirão Preto pela primeira vez em 2002, aos 13 anos de idade, devido a complicações decorrentes de uma combinação de problemas, como obesidade, intolerância à glicose, cefaleia e mielite viral, que havia sido diagnosticada no ano anterior. Apresentava queixa de diminuição da força muscular e levantou-se a hipótese de Hipertensão Arterial Sistêmica (HAS). Fez seguimento em diferentes ambulatórios: neurologia, fonoaudiologia, endocrinologia e diabetes, e clínica psicológica pediátrica. 
Em janeiro de 2006 foi atendido pela primeira vez no Ambulatório de Nutrologia, de onde foi encaminhado ao GRATA com suspeita de transtorno alimentar.

História da moléstia atual

A primeira consulta no GRATA ocorreu ainda no mês de janeiro de 2006. O paciente tinha, então, 17 anos de idade, $71 \mathrm{~kg}, 1,78 \mathrm{~m}$ de altura e IMC (Índice de Massa Corporal) de $22,41 \mathrm{~kg} / \mathrm{m}^{2}$ - portanto, eutrófico, isto é, dentro do padrão de normalidade. Apresentava como queixa inicial intensa perda de peso (46 kg em um intervalo de dez meses). Fernando afirmou que começara a perder peso após um quadro neuromuscular viral. No momento da entrevista para o presente estudo, seu desenvolvimento neuropsicomotor parecia estar se processando dentro dos limites da normalidade. Na época da internação pesava 117 kg e, por apresentar intolerância à glicose e HAS, foi orientado por médicos e nutricionistas a perder peso e a controlar a dieta. Desde então começou a fazer dieta por conta própria. Informou, durante a entrevista, que fazia cerca de seis refeições diárias, em pequenas quantidades, e que não fazia restrição específica a qualquer alimento. Incomodava-se com a possibilidade de aumento de peso e "voltar a ser gordo". Por isso pesava-se três vezes por semana. Negou episódios de vômito, náusea, diarreia e uso de laxantes ou remédios para emagrecer.

Fernando nasceu saudável de parto cesariano. De acordo com o relato de sua mãe, nasceu com 3,7 kg, porém em seu prontuário encontrava-se registrado o peso de 2,8 kg. A mielite viral e o quadro de enxaqueca foram tratados no Ambulatório de Neurologia, de onde foi encaminhado para a Endocrinologia, sendo aconselhado, então, a manter uma dieta devido à intolerância à glicose e à HAS. Fernando contou que, a princípio, mostrou-se muito resistente a seguir a dieta. Relatou, no entanto, que um dia, durante o atendimento na Endocrinologia, a médica lhe falou algo que encaixou na cabeça. Naquele dia se sentiu uma pessoa magra, seu pensamento mudou na hora, parecia que tocou tudo (...) Depois daquele dia, parece que foi embora. Tipo assim... soltar um foguete e ir embora, não desanimei, até hoje eu tô...

Desde então Fernando passou a seguir o regime prescrito pela médica. Porém, admitiu que, como desejava perder peso rapidamente, deixei a dieta de lado e fiz do meu jeito (...) Eu fui fazendo do meu jeito (...) eu tava comendo pouco pensando que eu tava comendo muito, entendeu?. Assim, ele seguia sua dieta restringindo a ingesta alimentar e fazendo exercícios físicos em demasia. Sentia-se frequentemente cansado, fraco, debilitado e com falta de ar, provavelmente sintomas de hipoglicemia. Chegou a desmaiar uma vez. Por outro lado, Fernando 
mencionou ter sentido felicidade enquanto emagrecia, mas ainda assim se incomodava com as pelancas, especialmente no abdômen, que achava que era gordura e por isso desejava emagrecer mais. Diz: Via que tava emagrecendo, mas... o excesso da... que eu olhava para baixo, eu pensava que tava engordando. Aí eu fui, fui, fui, fui... aí até hoje tá aí. Regime, regime, exercício, regime, exercício... chegava da escola cansado, fazia bicicleta, ia lá embaixo e andava, andava o dia inteiro, tava elétrico. E prosseguiu: Eu pensava que ia perder peso rápido assim, rapidinho assim. Todo alegre, enquanto que os outros seguiam a dieta certa, do meu jeito eu ficava cada dia mais magro. O corpo tava ficando daquele jeito que eu queria, mas assim, a saúde, assim, as vistas embaralhavam, olhava assim, cheio de estrelinhas...

Fernando começou a ser acompanhado no GRATA em janeiro de 2006. Referiu que foi transferido para fazer seu acompanhamento junto ao ambulatório de transtornos alimentares devido à “parte da nutrição”. Por esse relato observou-se que Fernando parecia não compreender que fora encaminhado ao GRATA porque tinha uma hipótese diagnóstica de transtorno alimentar e não apenas para realizar uma reeducação alimentar. No GRATA foi aconselhado a diminuir a frequência dos exercícios físicos e a seguir a dieta recomendada pela nutricionista.

Fernando relata que, a princípio, foi muito difícil ouvir as recomendações da nutricionista: Pra mim não resolvia nada... eu só queria fazer o meu jeito, eu tava emagrecendo, não queria que ninguém desse palpite, tava conseguindo aquela minha meta. Então ela falava, mas eu voltava a comer pouco, ou a minha mãe fazia eu comer à força e eu ia na bicicleta, queimava tudo e saía. Nesse segmento de fala fica evidente o uso recorrente de manobras compensatórias com a finalidade de aumentar o gasto energético.

\section{Um passo para a mudança}

Na medida em que persistia obstinadamente em sua dieta altamente restritiva e se engajava em exercícios físicos frenéticos, Fernando começou a achar que os músculos que gradualmente ganhava eram gordura: E ficava intrigado pensando: por que ganhava peso, quando estava comendo certinho?. A nutricionista, então, não apenas lhe explicou que ele estava ganhando massa muscular, como realizou o exame de bioimpedância com o intuito específico de mostrar-lhe concretamente o que ele, por si só, não estava dando conta de perceber, devido à distorção da imagem corporal. A bioimpedância utiliza um aparelho que consegue medir o percentual de massa magra e massa gorda do corpo por meio de uma corrente elétrica de baixa intensidade. 
Essa estratégia revelou-se muito importante para a evolução do tratamento. O rapaz conta o quanto foi bom poder ver o resultado, alegando que isso havia lhe ajudado muito: tô com o exame lá em casa até hoje. Tá fixado na geladeira...

Atualmente

Depois de quase um ano de tratamento no GRATA, Fernando ainda demonstrava preocupações relacionadas com o peso e com o corpo, mas apresentava alguma evolução no sentido de perceber seu corpo com menos distorção e de procurar seguir as orientações da equipe de saúde. Essa mudança sugere fortalecimento do vínculo de confiança com os profissionais que o atendiam, o que fortaleceu a aliança de trabalho. Fernando relatou que ainda praticava exercícios físicos com regularidade, mas não na mesma frequência e intensidade de antes. A obsessão pela magreza parecia ter arrefecido, mas a preocupação com o peso não estava suprimida. Contou que seguia o esquema alimentar recomendado pela nutricionista, mas ainda mantinha um controle rígido sobre a alimentação: Eu só como na hora certa para não sair do regime. Sem sair da dieta, não descontrola, senão... se descontrolar... Parece que o rapaz de hoje, com peso saudável, ainda tinha muito medo do menino obeso de outrora. Segundo Farrow (1992) e Kaufman (2006), a maioria dos homens com transtornos alimentares provavelmente já foram obesos, um achado que não tem equivalência nas mulheres acometidas.

Fernando mencionou ainda que, na época, se sentia bem consigo mesmo: Meu corpo pra mim hoje tá normal, antes eu achava muito defeito no meu corpo. Eu via uma coisinha, não, já tava engordando (...) eu já me vejo tudo normal, fiquei uma pessoa normal. Tá tudo certinho, assim, hoje.

\section{Uma compreensão psicodinâmica: próximo do corpo, longe do mundo...}

Os relatos de Fernando são sugestivos de uma personalidade em formação, com caráter rígido. Apresenta características de uma estrutura psíquica obsessivo-compulsiva, que lida com seus conflitos empregando defesas predominantemente do tipo restritivo-inibitórias. Isso transparece durante a entrevista, em suas reminiscências da infância (foi tudo certinho, graças a Deus), o que traduz seu perfeccionismo e meticulosidade. Essas características de personalidade também são encontradas no padrão de comportamento com que se identifica (sempre andei na linha), o que evidencia sua escrupulosidade, e no isolamento social 
resultante desse fechamento - eu não tenho muitos amigos -, o que aponta para a desconfiança que marca suas relações interpessoais. Esses indicadores emocionais nos remetem ao que a literatura traz com relação aos aspectos da personalidade: os homens com transtornos alimentares tendem a ser mais perfeccionistas e desconfiados do que as mulheres (Behar; De La Barrera; Michelotti, 2002).

A distorção da imagem corporal é evidenciada em relatos como: Eu tava comendo pouco pensando que eu tava comendo muito, entendeu?, ou quando afirmou que não acreditava nas pessoas quando lhe diziam que estava emagrecendo. Depois passou a perceber que estava perdendo peso, mas devido à pele flácida achava que estava engordando. A distorção com que percebia e sentia seu próprio corpo também estava presente nos excessos do regime que mantinha por conta própria e nos exercícios físicos desenfreados. Esses hábitos acarretaram consequências perniciosas para seu estado de saúde, que só foram percebidas tardiamente e após muita resistência.

Sua conduta inicial frente ao atendimento no GRATA foi de reserva e desconfiança. Mostrou-se refratário às recomendações da nutricionista: Pra mim não resolvia nada... eu só queria fazer o meu jeito, eu tava emagrecendo, não queria que ninguém desse palpite, tava conseguindo aquela minha meta. $\mathrm{O}$ uso de manobras com fins compensatórios foi intensificado: Eu ia na bicicleta, queimava tudo e saía.

Graças ao “êxito” que obteve com o fabuloso emagrecimento, passou a ser referência na pequena cidade interiorana em que reside. Fernando conta que passou até a receitar dietas para colegas do bairro em que mora. Obteve certa fama e prestígio social como um conhecedor do assunto, o que sem dúvida representou um ganho secundário do transtorno. Sua mãe confirmou essa versão. Relatou que todos na vizinhança ficaram impressionados com seu emagrecimento. Podemos levantar aqui outro questionamento: será que esse comportamento de “passar regimes” para outros não representaria mais uma forma de contrainvestir seu desejo de comer compulsivamente, conforme observou Jeammet (1999), de modo análogo a outras pessoas que sofrem de anorexia nervosa e adoram cozinhar, alimentar os membros da família e colecionar receitas?

Uma outra estratégia de contrainvestimento pode ser vista quando declarou que segue a dieta da nutricionista corretamente para não descontrolar, porque se descontrolar..., interrompendo a frase e deixando em suspenso um ponto de angústia. Isso sugere o temor de se descompensar, caso seu esquema defensivo rígido e altamente controlador perca a eficácia. Que medo seria esse ainda tão presente na mente de Fernando, ou melhor, que desejo inconsciente é esse que ainda estava tão atuante, em relação ao qual ele precisava se defender tenazmente, mantendo fortificações, para que não se tornasse consciente? Além disso, pa- 
rece-nos claro, nesse caso, a cisão operada entre o esquema corporal e o eu narcísico (COSTA, 2004), especialmente evidente quando o paciente relatou que: $O$ corpo tava ficando daquele jeito que eu queria, mas assim, a saúde assim, as vistas embaralhavam, olhava assim, cheio de estrelinhas...

\section{Considerações finais}

Consideramos que o caso clínico apresentado é exemplar no sentido de evidenciar a vulnerabilidade de jovens do sexo masculino à anorexia nervosa. Ao longo de seu desenvolvimento, Fernando sempre fora um menino obeso, chegando a apresentar problemas clínicos graves relacionados à obesidade. Por essa razão necessitou, em certo momento, fazer dieta por recomendação médica. No entanto, o que começou como uma dieta visando à recuperação de sua saúde e bem-estar físico e psicológico transformou-se, insidiosamente, em uma obsessão. A alimentação passou a ser o foco principal de preocupações, levando Fernando a acentuar seu isolamento social. Em seguida, sua vida passou a girar em torno de seu temor de voltar a ganhar peso, preocupação que contribuiu para o desencadeamento do transtorno alimentar, juntamente com as vulnerabilidades plantadas após o advento da puberdade.

Quanto mais Fernando emagrecia por conta própria - ou seguindo a dieta recomendada, mas de forma distorcida e acrescentando uma prática maciça de exercícios físicos diários -, mais seguro e feliz ele se sentia. Desse modo, quanto mais perdia peso, mais desejava emagrecer. Fernando mencionou que passou a se sentir mais seguro, em uma relação de satisfação com o próprio corpo, encontrando prazer em si mesmo (Sours, 1974) ao ver que tinha poder sobre seu próprio corpo e conseguia emagrecer tão rapidamente. O problema aqui se localiza na preocupação excessiva com a forma e o peso corporal, que o leva à distorção cognitiva e ao uso perverso da dieta que havia sido prescrita para preservar sua saúde. E o ganho secundário é a sensação de potência e plenitude narcísica que aufere ao se ver capaz de exercer controle sobre o peso e as medidas corporais.

O esquema alimentar se converteu em uma rigorosa restrição alimentar autoimposta, juntamente com o exagero com que se dedicava à prática de exercícios físicos, cujo principal motivador era a perda de peso, no ritmo acelerado em que isso se processou durante a evolução sintomática e a obstinação com que se dedicou aos seus rituais. Esses sintomas resultaram na transposição da dor psíquica para o corpo físico e, consequentemente, na dor do eu aprisionado clamando para ser visto e acolhido por meio dos sintomas. 
Fernando vem respondendo bem ao tratamento e apresenta uma evolução favorável. Parece estar mais consciente de si e aceitar melhor os limites de seu corpo, apesar de ainda apresentar preocupações recorrentes a esse respeito. Uma novidade auspiciosa na vida desse rapaz foi ter passado no primeiro teste admissional para a carreira militar. Anteriormente ao exame, tanto na entrevista com a pesquisadora, quanto durante atendimentos com a nutricionista, ele comentara sobre seu sonho de pilotar aviões e prestar serviço para a Aeronáutica. Relatou também suas preocupações com relação à prova de aptidão física que seria o último teste. Conseguiria aprovação? Seria considerado apto fisicamente? Temores e dúvidas em relação às suas próprias capacidades pareciam inundar sua mente, mas essas inquietações eram mascaradas pelo cortejo de fixações em torno da alimentação, peso, forma e aparência corporal (Andersen; Cohn; Holbrook, 2000).

De acordo com Bruch (1974), a anorexia nervosa em homens exige uma discussão à parte. Seus achados apontam que esses indivíduos, apesar de terem histórias de bom desempenho durante a vida, tendem a apresentar dúvidas acentuadas sobre sua adequação e competência pessoal. Assim, ao controlarem o peso, mantêm o sentimento de que podem controlar pelo menos a si próprios.

Em sua entrevista, a nutricionista considerou o quanto ter passado nesse primeiro teste parece ter aliviado Fernando e o estimulado a se cuidar melhor e de um modo saudável. É importante refletirmos sobre a possibilidade de esses adolescentes resgatarem sua capacidade de formular projetos de vida e cultivar seus sonhos. Transtornos alimentares são patologias que testemunham o fracasso da construção da autonomia, o que envolve várias dimensões, desde o autocuidado corporal e nutricional, até os setores do estudo, trabalho, amizades, lazer, namoro, esporte, atividades artísticas e culturais, planos em relação à vida profissional e afetiva, incluindo os relacionamentos interpessoais. Parece que um dos recursos que auxiliaram Fernando a atravessar e se libertar das amarras da anorexia nervosa foi manter uma zona da mente livre para sonhar e planejar seu futuro, o que o tem ajudado a transcender a concretude de seus sintomas e o apego excessivo à realidade que sua estrutura obsessiva determina. Assim como a flor de lótus, que nasce cheia de vida e beleza no brejo escuro, Fernando pôde renascer em meio a tantos temores e dores inerentes ao processo de crescimento. Seu estado nutricional e sua condição geral de saúde melhoraram significativamente, acompanhando a reorganização da personalidade e o remanejamento das defesas obsessivas.

Os dados sistematizados no presente estudo de caso confirmaram os achados da literatura de que adolescentes do sexo masculino também são vulneráveis aos transtornos alimentares, caso apresentem conflitos intra e interpsíquicos que predisponham a essa sintomatologia. Quando se veem diante da impossibilidade 
de usar criativamente o corpo como base corpórea da identidade, recorrem à formação do sintoma na tentativa de oferecerem uma resposta ou solução para o estado de paralisia psíquica em que se encontram.

Por fim, reforçamos a importância e necessidade de desenvolvimento de mais estudos que promovam reflexões mais aprofundadas acerca dos transtornos alimentares em sua interface com o universo masculino, contribuindo para ampliar as possibilidades de inclusão desses jovens nos serviços de atendimento especializado.

\section{Referências}

Andersen, A.E. Males with eating disorders. In: Yager, J.; Gwirtsman, H.E.; EdelsTEIN, C.K. (Org.). Special problems in managing eating disorders. Washington, DC: American Psychiatric Press, 1992. p. 87-118.

. Eating disorders in gay males. Psychiatric Annals, Charles Slack, v. 29, p. 206-212, 1999.

Andersen, A.E.; Holman, J.E. Males with eating disorders: challenges for treatment and research. Psychopharmacology Bulletin, v. 33, p. 391-397, 1997.

Andersen, A.E.; Cohn, L.; Holbrook, T. Making weight: men's conflicts with food, weight, shape \& appearance. Carlsbad: Gurze Books, 2000.

Behar, R.; De La Barrera, M.; Michelotti, J. Feminility, masculinity, androgyny and eating behaviours. Revista Médica de Chile, Santiago, v. 130, n. 9, p. 964-975, 2002.

BRUCH, H. Eating disorders: obesity, anorexia nervosa and the person within. Great Britain: Routledge \& Kegan Paul, 1974.

COPPERMAn, J. Review of the provision of healthy care services for men with eating disorders. London: Eating Disorders Association, 2000.

Costa, J.F. O vestígio e a aura: o corpo e consumismo na moral do espetáculo. Rio de Janeiro: Garamond, 2004.

Facchini, M. La imagen corporal en la adolescencia: es un tema de varones? Archivos Argentinos de Pediatría, Buenos Aires, v. 104, n. 2, p. 177-184, 2006.

Farrow, J.A. The adolescent male with an eating disorder. Pediatrics Annals, New York, v. 21, n. 11, p. 769-774, 1992.

GIL, A. Como elaborar projetos de pesquisa. 3. ed. São Paulo: Atlas, 1996.

JeAmmet, P. A abordagem psicanalítica dos transtornos das condutas alimentares. Trad. Mônica Seincman. In: Urribarri, R. (Org.). Anorexia e bulimia. São Paulo: Escuta, 1999. p. 20-49. 
Kaufman, A. Transtornos alimentares em homens. São Paulo, s/d. Disponível em: $<$ http://www.hcnet.usp.br/ipq/prato/biblioteca/arthur1.htm>. Acesso em: 24 abr. 2006. MoLL, E.U. Algunas reflexiones en torno a la comprensión psicoanalítica de la anorexia y la bulimia. Revista Chilena de Psicoanálisis, Santiago de Chile, v. 15, n. 2, p. 35-45, 1998.

\section{OMS - ORGANIZAÇÃO MUNDIAL DA SAÚDE. Classificação de Transtornos} Mentais e de Comportamento da CID-10: descrições clínicas e diretrizes diagnósticas. Porto Alegre: Artes Médicas, 1993.

Peres, R.S.; Santos, M.A. Sobre a utilização de estudos de caso na pesquisa científica e na prática profissional em Psicologia. In: Simon, C.P.; Melo-Silva, L.L.; SANTos, M.A. (Org). Formação em psicologia: desafios da diversidade na pesquisa e na prática. São Paulo: Vetor, 2005. p. 93-106.

Sours, J.A. The anorexia nervosa syndrome. International Journal of Psychoanalysis, v. 35, n. 4, p. 567-576, 1974.

Yin, R.K. Estudo de caso: planejamento e métodos. 3. ed. Porto Alegre: Bookman, 2005.

\section{Resumo}

(La experiencia corporal de un adolescente con trastorno alimentario)

A pesar del aumento de casos de jóvenes con anorexia nerviosa, esa temática todavía es un tabú en el universo masculino. El objetivo de este trabajo es investigar la manera como un joven con anorexia nervosa atípica vivencia su cuerpo e imagen corporal. Los datos fueron recolectados por entrevistas semi-estructuradas, audiograbadas y transcritas literalmente, con el paciente, su madre y nutricionista, además de consultas al prontuario médico. Se concluye que este joven presenta conflictos relacionados a su cuerpo e imagen corporal.

Palabras claves: Anorexia nervosa, sexo masculino, cuerpo, imagen corporal

(L’expérience corporelle d'un adolescent souffrant de désordre alimentaire)

En dépit de l'augmentation des cas d'anorexie nerveuse chez les jeunes, cette thématique reste encore un tabou dans l'univers masculin. Notre but est d'analyser comment un adolescent souffrant d'anorexie nerveuse atypique perçoit son corps et son image corporelle. La collecte des données a été faite à l'aide d'entretiens individuels semi-structurés enregistrés et transcrits littéralement, avec le patient, sa mère et la nutritionniste, ainsi que l'analyse du dossier médical. On conclut que ce jeune présente des conflits par rapport à son corps et à son image corporelle.

Mots clés: Anorexie nerveuse, sexe masculin, corps, image corporelle 
(The bodily experience of an adolescent boy with eating disorders)

Despite an increase in the number of adolescents suffering from anorexia nervosa, there is not doubt that obesity and overeating are still taboo among men and boys. This study consists of an investigation as to how an adolescent boy with atypical experiences in anorexia nervosa sees his body and body image. Semi-structured individual interviews with the patient, his mother and his nutritionist were carried out and his medical report was analyzed. The conclusion was that the young man experienced conflicts regarding his body and distortions of his bodily image.

Key words: Anorexia nervosa, men and boys, body, bodily image

Citação/Citation: AndRade, T.F. de; SAntos, M.A. A experiência corporal de um adolescente com transtorno alimentar. Revista Latinoamericana de Psicopatologia Fundamental, São Paulo, v. 12, n. 3, p. 454-468, set. 2009.

Editor do artigo/Editor: Prof. Dr. Manoel Tosta Berlinck.

Recebido/Received: 20.6.2008 / 6.20.2008 Aceito/Accepted: 4.3.2009 / 3.4.2009

Copyright: ( 2009 Associação Universitária de Pesquisa em Psicopatologia Fundamental/ University Association for Research in Fundamental Psychopathology. Este é um artigo de livre acesso, que permite uso irrestrito, distribuição e reprodução em qualquer meio, desde que o autor e a fonte sejam citados/This is an open-access article, which permits unrestricted use, distribution, and reproduction in any medium, provided the original author and source are credited.

Financiamento/Funding: Esta pesquisa foi financiada pela Fundação de Apoio à Pesquisa do Estado de São Paulo - Fapesp (São Paulo, SP, Brasil) / This research has been funded by the Fondation for Research Support of the State of Sao Paulo (São Paulo, SP, Brazil).

Conflito de interesses: Os autores declaram que não há conflito de interesses/The authors declare that has no conflict of interest.

\section{Thais Fonseca de Andrade}

Psicóloga; mestre pelo Programa de Pós-graduação em Psicologia da Faculdade de Filosofia, Ciências e Letras da Universidade de São Paulo - USP-RP (Ribeirão Preto, SP, Brasil); bolsista de mestrado da Fundação de Amparo à Pesquisa do Estado de São Paulo - Fapesp (São Paulo, SP, Brasil).

Rua Visconde de Inhaúma, 2029

14025-100 Ribeirão Preto, SP, Brasil

Fone: (16) 36230897

e-mail: thaisandrade@hotmail.com 


\section{Manoel Antônio dos Santos}

Psicólogo; mestre e doutor em Psicologia Clínica pelo Instituto de Psicologia da Universidade de São Paulo - USP-SP (São Paulo, SP, Brasil); professor do Programa de Pós-graduação em Psicologia da Faculdade de Filosofia, Ciências e Letras de Ribeirão Preto da Universidade de São Paulo - USP-RP (Ribeirão Preto, SP, Brasil); bolsista de produtividade em pesquisa do Conselho Nacional de Desenvolvimento Científico e Tecnológico - CNPq (Brasília, DF, Brasil); editor da revista Paideia (Ribeirão Preto, SP, Brasil).

Av. Bandeirantes, 3900 - Monte Alegre

14040-901 Ribeirão Preto, SP, Brasil

Fone: (16) 8132-9896

e-mail: masantos@ffclrp.usp.br 